\title{
Research on the Problems of Cross-border Electricity Supply Chain
}

\author{
Yunkai Zhai, Yixang Yang \\ Management Engineering Department, Zhengzhou University, Henan Province, China \\ 873567861@qq.com
}

Keywords: Cross-border electricity providers, Supply chain, Logistics

\begin{abstract}
With "The Belt and Road" initiative promoting the surrounding economic development, expanding the market, cross-border electricity business is facing new opportunities for development. This paper studies the problems existing in the supply chain of cross-border electricity supply business. Starting from the current supply chain model of cross - border electricity providers, this paper puts forward the existing problems of commodity quality, supply chain flexibility, cross - border logistics, payment risk and other aspects of the problem, and gives some countermeasures and suggestions.

\section{INTRODUCTION}

With the "The Belt and Road" construction of the advance, electric business enterprises are facing new opportunities for development, especially for crossborder electricity business, trade Unicom, tax incentives and other policies, no doubt for the development of cross-border electricity business has injected a strong impetus. Cross-border electricity supply chain is a model that combines general trade form, e-commerce platform and cross-border logistics supply chain (Mingjiang Shen, 2015). Logistics supply chain should be coordinated

logistics to the hands of consumers, the current majority of small businesses are using this model, such as Taobao's overseas purchasing, that is, by Alibaba to provide electricity providers Trading platform, consumers directly under orders, overseas business through some cross-border logistics directly to the goods sent to consumers. Many domestic electricity business platform already have such services, order direct mail supply chain because of its third-party turnover, to avoid the storage costs, while small quantities of orders can enjoy tax incentives, reduce the tax costs, suitable for In the B2C mode of trade, domestic personal purchasing usually use this model.
\end{abstract} with the development of cross-border electricity supply chain, the application of computer technology can be information Flow, capital flow to provide more efficient and efficient channels, and through e-commerce platform, cross-border electricity business greatly shorten the traditional foreign trade supply chain, improve the efficiency of resource allocation, saving time costs, broaden the overseas channels. Overseas suppliers, cross-border logistics, buyers, electricity business platform and other aspects of the supply chain are essential. This paper will study the status quo and existing problems of cross - border electricity supply chain and get corresponding countermeasures.

\section{CURRENT SITUATION OF SUPPLY CHAIN IN CROSS - BORDER ELECTRICITY SUPPLY}

At present, China's cross-border electricity supply chain has three main models, namely, direct mail orders, direct mail and bonded warehouse model, in addition, some large enterprises have begun to build overseas warehouses. The cost of the supply chain of the enterprise's cross-border electricity supply mainly includes the cost of warehousing, the cost of logistics, the cost of ordering and the cost of tax, and if you choose different supply chain models, there are some differences in cost structure and cost control.

\subsection{Order direct mail supply chain}

Order direct mail mode refers to the goods without a third party, directly from the enterprise through the

\subsection{Direct supply of goods supply chain}

Set direct mail mode is to batch orders together to purchase, sent to the domestic customs supervision warehouse, after passing the domestic cooperation courier delivery to consumers. The direct mail mode has a preliminary scale effect, relative to the order direct mail mode, it needs to go through this part of the storage, increased storage costs, while tax costs are higher, but because of the large number of goods, even spread to each cargo the logistics cost is low (Shen You, 2016). Set direct mail mode requires enterprises to have a certain turnover capacity, a more stable suppliers and customers, more large-scale electric business enterprises to use this model. At present, a large number of large domestic electric business enterprises have established overseas warehouses, can be a large number of orders centralized procurement, placed in overseas warehouses, centralized delivery, greatly improve the efficiency and shorten the transport time, so that consumer satisfaction has been large Increase the range.

\subsection{Bonded warehouse model}

Bonded warehouse model is to have been approved by the Customs goods in advance of the bonded warehouse, once the consumer orders, you can directly after the declaration by the domestic bonded warehouse delivery. Bonded warehouse model is the main import business of large and medium-sized enterprises to adopt the model, compared to direct mail mode, bonded warehouse has a front-end advantages, but also enjoy a certain tax incentives, but to a certain extent, increased 
storage costs. And because the bonded warehouse is the first purchase of goods storage, and then according to consumer demand delivery model, the type and quantity of goods, consumer preferences and other factors will have a greater impact on enterprises, how to avoid the backlog of goods to ensure that funds Chain operation is the application of bonded warehouse model enterprises must face the problem.

\section{PROBLEMS IN THE SUPPLY CHAIN OF CROSS - BORDER ELECTRIC MERCHANTS}

Although China's cross-border electricity supply chain already has a basic operating model, but its development is not mature, there are still many problems to be solved.

\subsection{Failing to guarantee the quality of goods}

Electric business enterprises are different from the offline entities, it has both self-employed goods, but also for other businesses to provide a platform. The quality of self-employed goods generally by the enterprise internal supervision, a series of quality management methods, the quality of self-employed goods can be guaranteed. However, the electricity business platform for the settled businessmen and not strictly screened, true and false goods mixed, the quality of goods uneven, especially in the C2C model of the transaction, customers and customers directly through the electricity business platform for the transaction, the basic quality of goods Not subject to regulation, shoddy, fake and shoddy goods are likely to exist, which will undoubtedly affect the consumer's consumer experience, reduce consumer satisfaction. Cross-border electricity business supply chain span longer, domestic and foreign law, language, culture and other differences, have made consumers do not understand the goods, the quality of goods can not be more effectively guaranteed, the purchase of qualified goods is cross-border Electric power supply chain an important part of how to ensure the quality of goods, enhance the intensity of supervision is to solve the problem.

\subsection{Long logistics cycle, high cost}

As the rapid development of domestic logistics, most consumers from the order to receive the goods only 3 to 5 days, but the cross-border logistics cycle is generally 15 days or even longer, and the sea Amoy, Daigou business model, Returns are also difficult to get an effective guarantee, a longer logistics cycle and lowquality after-sales service, no doubt makes the consumer satisfaction fell significantly. In addition, many power providers platform to provide cash on delivery services, in order to enhance customer trust, but the use of this payment method, long logistics cycle will lead to slow return of corporate funds, the company's liquidity and capital chain has a higher The request. And the logistics cycle occupies the entire supply chain for most of the time, making the entire supply chain operating cycle growth, reducing the response to environmental and market changes in the sensitivity of the supply chain to communicate between different enterprises to increase coordination, Business operations management also put forward higher requirements.

In addition, for the order to take the direct mail supply chain model of the enterprise, single-item logistics costs are high, making the cost of single-family goods increased, lower pricing reduced profit margins, higher pricing will reduce the competitiveness of enterprises. For enterprises that adopt the direct mail and bonded warehouse model, although the number of goods is large, the price allocated to each item is reduced, but the storage costs in the logistics process are increased. Enterprises need to reach a certain scale before they can use the scale Effect Reduces Logistics Costs. Today's access to information increased, the same business platform operators to operate similar products are more, lower trade barriers, resulting in the supply chain suppliers and sales companies bargaining power to reduce, but the consumer's choice increased, making the bargaining power of the consumers increases, the profit margins obtained by the enterprises through the sale and sale transactions are reduced, so reducing the logistics cost is an important measure to improve the enterprise profit.

\subsection{High financial risk}

E-commerce in recent years is to flourish, Lynx, Jingdong global purchase, Amazon and so on are in the rapid development of cross-border electricity business, but the electronic payment of the regulatory system is not perfect, the relevant laws and regulations have not yet fully established, it is easy to breed fraud behaviour, which is against the interests of consumers (Mingyu Wang and Qin Liao, 2014). At the same time, in the B2C mode, when the average consumer orders, it is according to the established exchange rate to determine the price, business in foreign purchases, but the risk of exchange rate changes afford by the third party payment platform, if the exchange rate fluctuations, cross-border electricity platform will be More difficult to offer the prices, the strategy and management experience of cross-border electricity business enterprises is still less (Dan Cui, 2017). Cross-border electricity business platform is the cross-border electricity supply chain and the traditional supply chain the most difference, procurement, logistics, transactions and so can not be separated from the business platform, the operation and management of electricity business for the entire cross-border electricity supply chain Vital.

\subsection{Lack of supply chain flexibility}

Traditional supply chain, suppliers, manufacturers and vendors are to retain a certain amount of inventory to deal with changes in the market environment. But for cross-border electricity providers, there is only a stock is not timely response to market supply is insufficient or not timely, but also need to establish a more flexible supply chain. Flexible supply chain is the enterprise has the ability to deal with and deal with the uncertainty of other enterprises and markets in the supply chain, this ability is not only for the logistics, information, capital flows can be more flexible response, but also includes business decision-making, human resources, Cultural construction and other aspects. At present, the supply 
chain of cross-border electricity providers lacks of flexibility, reflected in the low cost of logistics costs, lack of quality supervision, strong uncertainty, return service is not in place, these issues can be established through the flexible supply chain to be effective solve. Cross-border electricity supply chain has a little bit of structure, multi-point structure and the same platform structure model, different models have its flexibility reflected in different aspects, according to the size of enterprises, culture, market environment and other factors, one can determine the enterprise suitable supply chain model (Yuqiong Tao, 2017).

\section{COUNTERMEASURE ANALYSIS}

For the cross-border electricity supply chain supply chain problems, should be from overseas suppliers, buyers, logistics companies, electricity business platform and other aspects of the analysis, in addition, but also from the perspective of the overall supply chain to think. Enterprises of different sizes should choose different business models to determine the development goals and strategies.

Small and medium enterprises of funds, channels, customers and other resources are limited, you can choose a third-party logistics enterprises, many domestic logistics companies have been engaged in overseas business. In addition, the supplier's geographical location should be determined within a certain range, with some stable supply of goods to establish cooperation to ensure delivery capacity. And we should build the establishment of quality management system to ensure the quality of goods, according to the different types of business goods, the size of their own competitiveness to determine the appropriate electricity business platform.

Large-scale electric business enterprises, such as Jingdong, Amazon, etc., should use the advantages of enterprises, through the enterprise rather than buyers or individuals to obtain supply channels, large enterprises brand appeal can attract some high-end brands to provide long-term stable supply, invite these brands settled But also can attract more consumers to expand their influence, is a win-win way. Self-logistics, the establishment of overseas warehouses, bonded warehouses, etc. is also a good choice, large-scale electricity business enterprises strong chain of funds, the future development of stability, investment in overseas warehouses and other pre-need a larger capital investment, but in the long run, Reduce the logistics costs, but also to ensure a more stable supply chain. However, large-scale electric business enterprises because of its number of transactions, the amount of large, in the face of a large number of enterprises, supply chain flexibility to reduce, through the establishment of appropriate corporate culture, signed a more flexible contract to enhance supply chain flexibility.

\section{REFERENCES}

[1] Yuqiong, Tao, 2017. China's cross-border electricity providers in the supply chain flexible optimization strategy research, Reform and strategy. 33 (08), pp.134-137.

[2] Dan, Cui, 2017. Supply chain finance in cross-border electric business foreign exchange risk management application, Modern business. (20), pp.109-110.

[3] Shen, You, 2016. Logistics supply chain structure in the cross-border electric business in the selection and optimization. Modern business. (29), pp. 10-12.

[4] Mingjiang, Shen, 2015. Cross-border electric business how to ensure "supply chain", China Customs. (10), pp.62-66.

[5] Mingyu, Wang and Qin, Liao, 2014. China's cross-border electricity business major problems and countermeasures, China Business. (33), pp.76-80. 